\title{
BMJ Open Access to healthcare and financial risk protection for older adults in Mexico: secondary data analysis of a national survey
}

\author{
Svetlana V Doubova, ${ }^{1,2}$ Ricardo Pérez-Cuevas, ${ }^{3}$ David Canning, ${ }^{4}$ Michael R Reich ${ }^{5}$
}

To cite: Doubova SV, PérezCuevas R, Canning D, et al. Access to healthcare and financial risk protection for older adults in Mexico: secondary data analysis of a national survey. BMJ Open 2015;5:e007877.

doi:10.1136/bmjopen-2015007877

- Prepublication history and additional material is available. To view please visit the journal (http://dx.doi.org/ 10.1136/bmjopen-2015007877).

Received 5 February 2015

Revised 10 June 2015

Accepted 15 June 2015
CrossMark

For numbered affiliations see end of article.

Correspondence to Dr Svetlana V Doubova; svetlana.doubova@gmail.com

\section{ABSTRACT}

Objectives: While the benefits of Seguro Popular health insurance in Mexico relative to no insurance have been widely documented, little has been reported on its effects relative to the pre-existing Social Security health insurance. We analyse the effects of Social Security and Seguro Popular health insurances in Mexico on access to healthcare of older adults, and on financial risk protection to their households, compared with older adults without health insurance.

Setting: Secondary data analysis was performed using the 2012 Mexican Survey of Health and Nutrition (ENSANUT).

Participants: The study population comprised 18847 older adults and 13180 households that have an elderly member.

Outcome measures: The dependent variables were access to healthcare given the reported need, the financial burden imposed by health expenditures measured through catastrophic health-related expenditures, and using savings for health-related expenditures. Separate propensity score matching analyses were conducted for each comparison. The analysis for access was performed at the individual level, and the analysis for financial burden at the household level. In each case, matching on a wide set of relevant characteristics was achieved.

Results: Seguro Popular showed a protective effect against lack of access to healthcare for older adults compared with those with no insurance. The average treatment effect on the treated (ATET) was ascertained through using the nearest-neighbour matching $(-8.1 \%$, t-stat -2.305$)$ analysis. However, Seguro Popular did not show a protective effect against catastrophic expenditures in a household where an older adult lived. Social Security showed increased access to healthcare (ATET -11.3\%, t-stat -3.138), and protective effect against catastrophic expenditures for households with an elderly member (ATET $-1.9 \%$, t-stat -2.178).

Conclusions: Seguro Popular increased access to healthcare for Mexican older adults. Social Security showed a significant protective effect against lack of access and catastrophic expenditures compared with those without health insurance.

\section{Strengths and limitations of the study}

- We conducted a propensity score-matching analysis that reduces overt selection bias owing to observed differences among study groups.

- After matching on observable characteristics, Seguro Popular was inferior to Social Security health insurance both in providing access to healthcare and in assuring financial risk protection for Mexican older adults.

- The limitation of this study is that financial burden variables consider household out-of-pocket health-related expenditures that can include those of other household members; however, it seems reasonable to assume that older adults spent more for healthcare than younger household members.

- Propensity score matching is a statistical approach that reduces overt selection bias owing to observed differences among study groups; nevertheless, it does not permit controlling for hidden unobserved differences.

\section{BACKGROUND}

In Mexico, older adults are a growing vulnerable group with underprivileged socioeconomic conditions, poor health status and inequitable access to healthcare. During recent decades, the population of aged 60 years and above has experienced an annual growth rate of $3.8 \%$. Currently, older adults account for about $10 \%$ of the population. $^{1}$

Older adults have a steady increase in their social and health needs. In Mexico, a large proportion lives below the poverty line; only one in four receives pensions from Social Security (SS) and about $30 \%$ receive monetary support from the national programme '65+' (for people of 65 years and over). The minimum pension is equivalent to a 1997 minimum wage value indexed to inflation (about US\$167 per month in 2012). ${ }^{2}$ 
The monetary support of the ' $65+$ ' programme consists of US $\$ 80$ provided every 2 months. ${ }^{3}$

The socioeconomic conditions and availability of health insurance (HI) for older adults are major determinants of the differential use of health services and access to medicines. ${ }^{4}{ }^{5}$ From this standpoint, the Mexican population can be divided into three main groups: those affiliated with SS; those affiliated with Seguro Popular (SP); and those who do not have any HI. The right to SS is linked to employment status. SS affiliation follows a social $\mathrm{HI}$ scheme in which workers with a formal job must make contributions through a progressive payroll tax rate. In return, affiliates have the right to receive full social, economic (pensions and disability leaves) and health benefits that include healthcare and provision of medicines. Currently, approximately 71 million people in Mexico are affiliated with SS institutions, which include the Mexican Institute of Social Security (IMSS), the Institute for Social Security and Services for State Workers (ISSSTE), and other SS institutions. ${ }^{6}$

The population not affiliated with the SS is the target of SP. The group comprises the non-salaried population (informal sector workers and unemployed) and people living in rural areas. The financial resources for health and social programmes for this group come from general taxation, and affiliates receive benefits for free. SP finances most of the healthcare of 53.3 million people who generally receive services at the Ministry of Health $(\mathrm{MoH})$ facilities. ${ }^{7}$

The principal purposes of SP are to increase public healthcare expenditures, increase efficiency, protect families against financial risks of health expenditures, and incentivise the demand side. SP seeks to provide HI to individuals so that they can use healthcare services whenever necessary and without out-of-pocket expenditures or copayments. Despite these efforts, SP has not reached its objectives. In 2013, Mexico still had 21 million people without medical insurance (roughly $18 \%$ of the national population) ${ }^{8}$ Also, the out of pocket health-related expenditures (OOPHE) are still high among SP affiliates despite substantial increases in the healthcare budget. During the period 2003-2010, OOPHE decreased from $52.9 \%$ to $47 \%{ }^{9}$

The figures for the population affiliated to SS, SP, and without HI are higher than those for the total Mexican Population. These discrepancies are due to (1) flaws of institutional affiliation registries; (2) lack of knowledge of beneficiaries about their affiliation to a public HI; (3) overlapping of HIs to which beneficiaries are affiliated, since being affiliated with any public $\mathrm{HI}$ is not mutually exclusive and affiliation is dynamic. ${ }^{9}$

Older adults have a high prevalence of chronic diseases and disability; they are the most dependent age group on medical care for maintaining a decent quality of life, and the heaviest users of medical services. ${ }^{10}$ In Mexico, the 2010 National Survey on the Perception of Disability reported that $27 \%$ of older adults had a physical or mental disability. ${ }^{11}$
Current Mexican health policies for older adults vary for different social groups. For example, social and healthcare benefits of SS are more generous than the benefits of SP. SP has a predefined package of primary and secondary care interventions, and a limited treatment package for certain high-cost diseases such as cervical and breast cancer, non-Hodgkin lymphoma, prostate cancer, corneal transplant and cataract surgery. SP does not cover other high-cost conditions for older adults.

To date, the magnitude of the differences in access and in financial burden of healthcare among older adults affiliated to SS, SP and those without $\mathrm{HI}$ is unknown. These differences represent potentially avoidable inequities that systematically place socially disadvantaged groups of older adults without SS at a further disadvantage in health. ${ }^{12}$

The conceptual framework for this study is based on Anderson's behavioural model of health services use. ${ }^{13}$ The central concept of the framework is access, which means the actual use of personal healthcare services and everything that facilitates or impedes their use. This framework takes into account the contextual and individual determinants, which in turn are divided into predisposing and enabling characteristics. The individual determinants that refer the predisposing characteristics are age/gender, health needs. The enabling characteristics are those related to the capability of the individual to afford the services and the effective price of healthcare to the patient. The enabling characteristics in our study imply having HI, which in this case means to be affiliated with SP or SS. The enabling characteristics might also be related to OOPHE. Under this framework, it is possible to learn about realised access, which means the actual use of services and reduction of OOPHE.

This study analyses the effects of SS and SP HI on access to healthcare of older adults, and on the financial risk protection to their households, compared with each other and to those without HI. Nonetheless, we hypothesised that both HIs increase access to healthcare and provide financial protection against health expenditures. We also assumed that the effect on access and OOPHE of those affiliated to SS was higher (SSHI vs without HI) when compared indirectly with SP (SPHI vs without HI) due to the smaller package of benefits that SP provides to its affiliates.

\section{METHODS}

\section{Study design and data source}

A secondary data analysis was performed using the 2012 Mexican Survey of Health and Nutrition (ENSANUT 2012 for its acronym in Spanish). The survey has national, state and urban-rural representativeness. ENSANUT 2012 used probability-based complex sample designs to collect data on demographic and socioeconomic characteristics, health status and healthcare-related variables. The sample design followed 
a probabilistic multistage process. The specific details of the sampling approach are published elsewhere. ${ }^{14}$ All the information for the analysis comes from the ENSANUT 2012 household questionnaire.

\section{Variables}

The independent variable for this study was type of $\mathrm{HI}$ reported by older adults, with three categories: (1) SSHI (eg, IMSS and other SS institutions); (2) SP and other governmental non-contributory social SPHI (SP, IMSS-Oportunidades); (3) not having or not remembering if they have HI. For this analysis, this group was considered as older adults without HI.

The study examined two main dependent variables:

- Older adults with access to healthcare were those who needed and reported having utilised healthcare services (modified from the method reported by Wagner et $a l) .{ }^{15}$ Older adults lacking access were those who reported the need, but did not utilise healthcare services. Older adults with the 'need for healthcare' were defined as those who reported a perceived need for healthcare in the past 15 days due to non-infectious or infectious disease, injury or poisoning.

- The financial risk protection regarding the burden of healthcare expenditures during the past year was analysed through two indicators:

- Utilisation of savings, borrowing money, or selling assets to pay for healthcare expenditures. ${ }^{15}$

- Catastrophic expenditures were those healthcare expenditures accounting for $40 \%$ or more of total household capacity to pay, as defined by the WHO, considering the household capacity to pay as the total expenditures minus food expenditures. ${ }^{16}$

OOPHE included hospitalisation expenditures, health professionals, medicines-related expenditures, laboratory tests, healers and traditional medicine, dental care, hearing aids, eyeglasses and prostheses. These expenditures were reported for the past 3 months and multiplied by 4 as an approximation for the past year.

Total household expenditures were calculated as the sum of food and other domestic expenditures during the past week; these were multiplied by 52 as an approximation for the past year. Utilities-related expenditures (eg, electricity and rent) during the past month were multiplied by 12; total household expenditures were calculated by adding these two sums to healthcare expenditures.

\section{Covariates}

Sociodemographic characteristics of older adults were sex, age, ethnicity, illiteracy (inability to read or write), living with or without a life partner, number of household members, place of residence (rural, urban or metropolitan), and degree of marginalisation of the place of residence (very low/low and middle/high/very high). The 2010 marginalisation index for Mexico (based on access to basic infrastructure services, housing conditions, education attainment and wage earnings) at the local level served as a criterion for marginalisation. ${ }^{17}$

The socioeconomic indicator was previously constructed through imputing deciles of income level to the households in the ENSANUT 2012. The indicator was built using demographic and socioeconomic characteristics; it was based on the National Income and Expenditure Survey 2010 and presented by quintile. ${ }^{18}$

Other covariates were self-reported physical and mental limitations, diagnosis of chronic disease, and hospitalisation within the past year.

The following additional study variables were included to describe better some characteristics and barriers that older adults reported for access to healthcare:

Sources of income such as formal employment, informal employment, retirement or pension and monetary support from governmental programmes, or from other sources.

Health problems that occurred in the past 15 days before the survey, such as infectious or non-infectious diseases, injury or other condition, and perception of the severity (mild, moderate or severe).

Utilisation of healthcare services and medicines in the past 15 days, type of usual healthcare provider, such as SS institution, Ministry of Health or other public provider, private health services or others (like healers, homoeopaths, etc).

Perceived barriers to healthcare access for those who reported having a health problem but who did not use healthcare services. The barriers were geographic (far from the household), organisational (slow administrative process, limited health services schedule, long waiting time), opinions about providers' behaviours (previous experience of being treated badly, lack of confidence), personal (the older adult lacked somebody to accompany him to visit the medical doctor, lack of time), and financial (not enough money for transportation or for paying for the visit and medicines).

\section{Study population}

Figure 1 depicts selection of the study population. ENSANUT 2012 was applied to 194923 individuals in 50528 households (87\% response rate), from whom 19 777 were aged 60 years and above, which according to the expansion factors represented more than 10 million older adults. The analysis excluded $61(0.3 \%)$ older adults with private HI, $215(1.1 \%)$ affiliated with two different HIs, and $654(3.3 \%)$ with more than $20 \%$ of missing data on OOPHE and other household expenditures. In the latter case, it was not possible to calculate the total expenditures and financial burden variables. The descriptive analysis of the study groups included 18847 older adults. The inferential analysis was performed according to the characteristics of each dependent variable. The analysis of access was performed at the individual level. It included 3111 older adults who reported a perceived need for healthcare in the past 15 days. The analysis at the household level was 
Figure 1 Selection of the study population. ENSANUT, Mexican Survey of Health and Nutrition; $\mathrm{HI}$, health insurance; OOPHE, out of pocket health-related expenditures; SPHI, Seguro Popular health insurance; SSHI, Social Security health insurance.

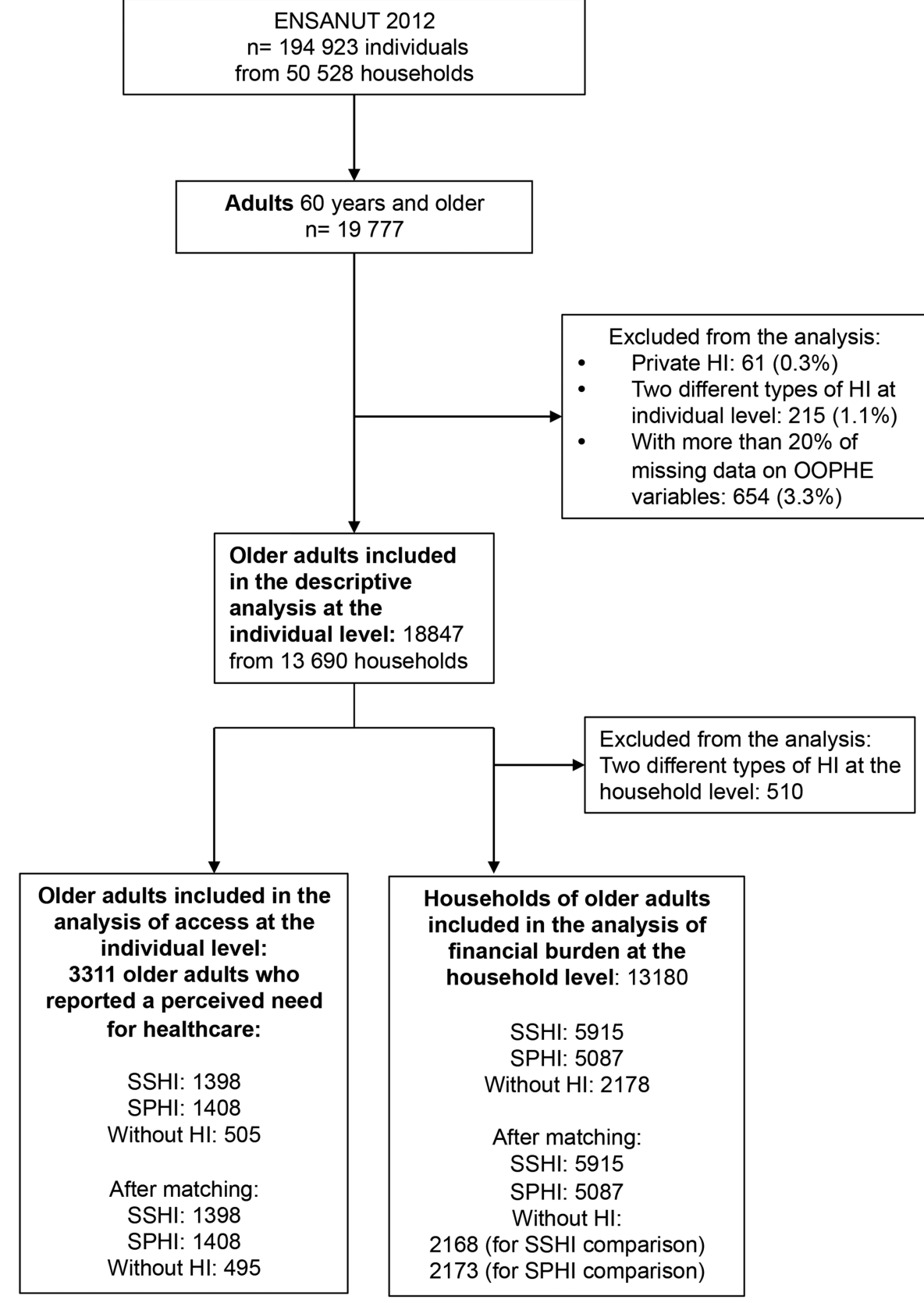

performed with 13180 households, as we also excluded 510 households that had older adults from different HI groups.

\section{Statistical analysis}

Comparisons of study variables among the three HI groups were performed using the $\chi^{2}$ test for categorical variables. Data were weighted using the survey sampling weights.

Propensity score matching (PSM) served to estimate the effect of HI on the dependent variables. The PSM technique allows the effect of a programme or treatment to be evaluated through the use of observational data from non-randomised studies in which selection bias is highly possible. PSM reduces this bias by modelling the conditional probability of participating in the programme or treatment group (T) (in our case being affiliated with a $\mathrm{HI}$ ) on the basis of background characteristics $(\mathrm{X})$ unaffected by the programme: $\mathrm{P}(\mathrm{X})$ $=\operatorname{Pr}(\mathrm{T}=1 \mid \mathrm{X})$. The individuals of both groups should then be matched on the basis of the propensity score ${ }^{19}$ Using PSM, older adults affiliated to SSHI can be compared with observationally similar older adults with SPHI or older adults without HI. The necessary assumptions for this technique are (1) conditional independence and (2) presence of a common support (overlap between propensity score distributions of treatment and comparison groups).

Separate PSM analysis was conducted for each of the following two combinations: SSHI versus without $\mathrm{HI}$ and SPHI versus without HI. The reference group was the group without HI. We followed the World Bank 
recommendations $(2010)^{19}$ to use the 'pscore' command to generate the propensity score. The 'pscore' command allows considering the survey weights in the analysis to achieve treatment-effect estimates. Such estimates are generalisable to the original survey target population. ${ }^{20}$ Selection of covariates for the propensity score model was based on the literature review that reported the association of such covariates with the

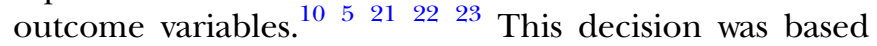
on the recommendation of Rubin and Thomas that a covariate should only be excluded from the analysis if there is a consensus that it is either unrelated to the outcome or not a proper covariate. ${ }^{24}$ Furthermore, variables that might be the result of having HI (eg, hospitalisation) were excluded from the PS model. Online supplementary appendixes 2 and 3 provide the information about the PS models.

The analysis of access was performed at the individual level, whereas the financial burden was analysed at the household level. Therefore, for the financial burden analysis, the covariates measured at the individual level were excluded (sex, age), or identified at the household level, as a household with at least one older adult with physical or mental limitations; household with at least one older adult with chronic disease, and so on.

To generate the PS and analyse a common support and the matching quality, the 'pscore' command uses the stratification method. It estimates the score by subdividing the population into 'blocks' (quintiles). It requires that the balance of covariates be achieved within each stratum in order to satisfy the balancing property of the PS. The presence of a common support and the matching quality was ascertained. We used the nearest-neighbour method ('attnd' command) to estimate the average treatment effect on the treated (ATET). The robustness of the results was verified by applying radius matching (with radius 0.001) and Kernel matching techniques ('attr' and 'attk' commands, respectively). ${ }^{19}$ The STATAV.12 software was used.

\section{RESULTS}

Table 1 shows the sociodemographic characteristics of older adults by HI; $51.3 \%$ of participants reported having SSHI and $30.9 \%$ reported having SPHI, whereas $17.8 \%$ were without HI. There were fewer women and more aged older adults in the group without HI. SPHI affiliates and those without $\mathrm{HI}$ were the most vulnerable. These groups had higher percentages of indigenous and illiterate people living without a life partner in rural and high marginalisation areas, and were in the lowest socioeconomic quintiles than older adults affiliated with SSHI. Most of the older adults reported using the health services to which they were affiliated. The group without HI more often used private doctors $(66.1 \%)$ or public facilities $(33.0 \%)$.

Pensions were the primary source of income for SSHI affiliates $(31.9 \%)$, followed by paid work $(21.3 \%)$ and monetary support (17.4\%). However, for SPHI affiliates and those without $\mathrm{HI}$, the primary source of income was monetary support, followed by paid work; $41.6 \%$ of older adults without HI, $30.3 \%$ with SPHI and $38.0 \%$ with SSHI did not specify the source of income.

Table 2 describes health problems and utilisation of health services and medicines. Older adults affiliated with SSHI and SPHI reported physical and mental limitations (36.7\% and $39.6 \%$, respectively) more often than did the group without HI $(33.5 \%)$. The same tendency was evident for those who were diagnosed with a chronic disease in the past year $(19.3 \%, 17.4 \%$ vs $12.9 \%)$.

The SPHI group reported the highest proportion of older adults with a health problem within the past 15 days before the survey and the need for healthcare. The SSHI group and the group without HI reported low percentages. The SSHI and SPHI groups reported noninfectious diseases more often. The group without HI reported slightly higher percentages of severe health problems $(38.3 \%)$ than did the SPHI group $(36.9 \%)$ and the SSHI group $(33.1 \%)$. The highest percentage of older adults who utilised health services and used medicines were from the SSHI group ( $78.4 \%$ and $87.8 \%$ ), followed by SPHI $(60.2 \%$ and $79.1 \%)$ and then the group without HI $(55.3 \%$ and $78.9 \%)$. Also, the highest proportion of hospitalised patients was from the SSHI group.

Table 3 shows access to healthcare, perceived barriers for access, and financial burden. Older adults with SSHI reported the highest access, followed by those with SPHI and without HI (90.2\%, $74.6 \%$ and $70.9 \%$, respectively). The groups without HI and with SPHI reported financial barriers for access to healthcare $(57.8 \%$ and $38.7 \%$, respectively) and personal barriers $(21.0 \%$ and $30.4 \%$, respectively). The other barriers of the SSHI group were personal $(33.5 \%)$, organisational $(12.4 \%)$, and related to the lack of satisfaction with providers' behaviour $(12.0 \%)$.

Regarding the financial burden, $3.9 \%$ of households without HI reported catastrophic expenditures. This figure was higher than that reported by HI groups (SSHI 2.2\% and SPHI 3.2\%). Furthermore, households from the SPHI group and without HI reported more often using savings, borrowing money or selling assets to pay for healthcare.

Online supplementary appendix 1 provides detailed information about total household expenditure, household capacity, health-related household expenditure and financial resources that were used for paying for healthcare.

Table 4 shows the results of PSM for evaluating the effect of HI on the outcome variables for two combinations: SSHI versus without HI, and SPHI versus without HI. SSHI and SPHI showed a protective effect against lack of access to healthcare, whereas the average treatment effect (ATET) using the nearest-neighbour matching was $-8.1 \%$ (t-stat -2.305$)$ for SPHI and $-11.3 \%$ (t-stat -3.138 ) for SSHI. 
Table 1 Sociodemographic characteristics of older adults by type of health insurance

\begin{tabular}{|c|c|c|c|}
\hline \multirow[b]{2}{*}{ Characteristic } & \multicolumn{3}{|c|}{ Health insurance (HI) } \\
\hline & Social Security & Seguro Popular & Without HI \\
\hline \multicolumn{4}{|l|}{ Number of respondents } \\
\hline Unweighted & 8404 & 7256 & 3187 \\
\hline Weighted & 5156870 & 3106183 & 1789322 \\
\hline$\%$ & $51.3(49.6,53.0)$ & 30.9 (29.5 to 32.3$)$ & $17.8(16.7$ to 18.8$)$ \\
\hline Sociodemographic characteristics & Weighted \% & Weighted \% & Weighted $\%$ \\
\hline Sex female & $54.4(53.02,55.5)$ & $52.7(51.5,53.9)$ & $51.8(49.9,53.6)$ \\
\hline \multicolumn{4}{|l|}{ Years of age* } \\
\hline $60-74$ & $73.4(71.8,74.9)$ & $73.7(72.2,75.1)$ & $70.7(68.5,72.8)$ \\
\hline $75-84$ & $20.6(19.3,21.9)$ & $20.7(19.5,22.1)$ & $20.7(18.9,22.5)$ \\
\hline$\geq 85$ & $6.0(5.4,6.8)$ & $5.6(4.9,6.3)$ & $8.6(7.3,10.1)$ \\
\hline Ethnicity (indigenous)* & $17.3(15.8,18.9)$ & 30.3 (27.9 to 32.8$)$ & $25.7(23.0,28.6)$ \\
\hline Illiteracy (cannot read or write) ${ }^{*}$ & $12.0(10.9,13.2)$ & $36.3(34.5,38.1)$ & $29.8(27.6,32.0)$ \\
\hline Living without a life partner (widowed, divorced, single)* & $36.7(35.0,38.4)$ & $37.7(35.9,39.5)$ & $45.3(42.7,47.9)$ \\
\hline Size of household, ${ }^{*}$ mean $(95 \% \mathrm{Cl})$ & 3.5 (3.5 to 3.6$)$ & $3.6(3.5$ to 3.7$)$ & $3.7(3.6$ to 3.8$)$ \\
\hline \multicolumn{4}{|l|}{ Place of residence* } \\
\hline Rural & $9.5(8.4,10.6)$ & $46.2(43.8,48.6)$ & $26.5(24.1,29.1)$ \\
\hline Urban & $16.0(14.3,17.8)$ & $25.0(22.9,22.2)$ & $23.0(20.5,25.6)$ \\
\hline Metropolitan & $74.5(72.4,76.5)$ & $28.8(26.4,31.3)$ & $50.5(47.2,53.7)$ \\
\hline High marginalisation of the place of residence* & $9.1(8.1,9.8)$ & $35.8(33.5,38.1)$ & $22.2(19.9,24.5)$ \\
\hline \multicolumn{4}{|l|}{ Quintile of socioeconomic status* } \\
\hline $1 \mathrm{st}$ & $12.1(11.0,13.4)$ & $40.3(38.2,42.5)$ & $31.1(28.4,33.9)$ \\
\hline 2nd & $16.8(15.3,18.4)$ & $23.6(22.0,25.2)$ & $20.4(18.3,22.8)$ \\
\hline 3rd & $20.5(19.1,22.0)$ & $17.6(16.2,19.2)$ & $18.5(16.5,20.6)$ \\
\hline 4th & $25.7(24.0,27.3)$ & $13.4(12.1,14.8)$ & $15.9(14.0,17.9)$ \\
\hline 5th & $24.9(22.6,27.3)$ & $5.1(4.3,6.0)$ & $14.1(11.7,16.9)$ \\
\hline \multicolumn{4}{|l|}{ †Health services that older adults usually attend } \\
\hline Social Security institutions* & $90.6(89.3,91.7)$ & $0.8(0.5,1.3)$ & $1.1(0.7,1.7)$ \\
\hline $\begin{array}{l}\text { Ministry of health, or other providers from the } \\
\text { governmental non-contributory social HI programmes* }\end{array}$ & $3.6(3.0,4.3)$ & $87.4(85.9,88.8)$ & $33.0(30.3,35.8)$ \\
\hline Private providers* & $16.8(15.4,18.3)$ & $22.0(20.3,23.7)$ & $66.1(63.4,68.8)$ \\
\hline Healers, homoeopaths, etc. & $0.12(0.03,0.5)$ & $0.1(0.02,0.25)$ & $0.4(0.17,0.87)$ \\
\hline \multicolumn{4}{|l|}{$\ddagger$ Primary sources of income } \\
\hline Paid work* & $21.3(19.9,22.8)$ & $26.5(25.0,27.9)$ & $28.9(26.7,31.3)$ \\
\hline Retirement or pension* & $31.9(30.1,33.8)$ & $1.3(1.0,1.7)$ & $3.0(2.1,4.1)$ \\
\hline Monetary support from the government programmes* & $17.4(15.9,19.1)$ & $46.6(44.8,48.5)$ & $26.5(24.2,28.9)$ \\
\hline Monetary support from others* & $4.8(4.2,5.5)$ & $8.1(7.1,9.2)$ & $7.1(6.0,8.4)$ \\
\hline Did not specify their source of income* & $38.0(36.2,39.9)$ & $30.3(28.7,31.9)$ & $41.6(39.0,44.2)$ \\
\hline
\end{tabular}

${ }^{*} \mathrm{p}<0.05$.

$\dagger 11.7 \%$ older adults reported more than one health service that they usually attend that was different from their $\mathrm{HI}$.

$\$ 8.4 \%$ of older adults reported more than one other source of income.

Furthermore, SSHI showed a protective effect against catastrophic expenditures for the households in which an older adult lived (ATET $-1.9 \%$, t-stat -2.178), whereas SP did not show such protective effects. These results were consistent after applying the different matching techniques. Regarding the effect of both HI on using savings to pay OOPHE, the results were inconsistent for SSHI and not statistically significant for SPHI.

\section{DISCUSSION}

This study has two major contributions to the analysis of $\mathrm{HI}$ in Mexico. First is its focus on the elderly who are more vulnerable to health shocks. Second, it allows the indirect comparison of SP with SS. Previous studies evaluated the effects of SPHI affiliation on utilisation of health services and catastrophic OOPHE in comparison with the population without HI. The results were positive, showing the protective effect of SPHI. ${ }^{25} 26$ The present study compared the population affiliated with SPHI and with SSHI with those without HI, allowing the indirect comparison of the relative effectiveness of both health insurances.

This study found that in Mexico, SP HI showed a protective effect against lack of access to healthcare for Mexican older adults. SS HI showed a significant protective effect against lack of access and catastrophic expenditures compared with those without HI.

The study also showed that the socioeconomic conditions of older adults without HI and with SPHI are more 
Table 2 Older adults' health problems and utilisation of health services and medicines by type of health insurance (ENSANUT 2012)

\begin{tabular}{|c|c|c|c|}
\hline & \multicolumn{3}{|c|}{ Health insurance (HI) } \\
\hline & Social Security & Seguro Popular & Without HI \\
\hline \multicolumn{4}{|l|}{ Number of respondents } \\
\hline Unweighted & 8404 & 7256 & 3187 \\
\hline Weighted & 5156870 & 3106183 & 1789322 \\
\hline$\%$ & $51.3(49.6,53.0)$ & $30.9(29.5,32.3)$ & $17.8(16.7,18.8$ \\
\hline Health problems & Weighted \% & Weighted \% & Weighted \% \\
\hline Physical and/or mental limitations for: & $36.7(34.9,38.6)$ & $39.6(37.6,41.7)$ & $33.5(31.1,36.0$ \\
\hline Sight, even when wearing glasses* & $13.7(12.5,15.0)$ & $17.1(15.7,18.5)$ & $12.4(10.9,14.2$ \\
\hline Hearing, even when using a hearing aid* & $8.2(7.4,9.0)$ & $9.5(8.8,10.5)$ & $7.2(6.2,8.3)$ \\
\hline Walking, moving and climbing stairs* & $27.4(25.8,29.0)$ & $29.0(27.3,30.8)$ & $23.9(21.8,26.1$ \\
\hline Dressing, bathing or eating & $4.1(3.6,4.7)$ & $4.5(3.8,5.2)$ & $3.7(2.9,4.8)$ \\
\hline Speaking, communicating or conversing & $1.9(1.5,2.3)$ & $2.3(1.8,2.8)$ & $2.1(1.5,2.9)$ \\
\hline Paying attention and learning simple things & $1.6(1.3,2.0)$ & $2.1(1.7,2.7)$ & $2.2(1.6,3.2)$ \\
\hline Understanding what other people say* & $1.3(1.0,1.7)$ & $1.9(1.5,2.3)$ & $2.0(1.5,2.9)$ \\
\hline Diagnosis of chronic disease in the last year* & $19.3(17.9,20.8)$ & $17.4(15.9,19.1)$ & $12.9(11.2,15.0$ \\
\hline Health problem that happened within 15 days before the survey* & $19.2(17.8,20.5)$ & $24.5(23.0,26.1)$ & $18.8(16.9,20.8$ \\
\hline Healthcare need ${ }^{*}$ & $16.8(15.6,18.2)$ & $21.3(19.8,22.8)$ & $16.1(14.4,17.9$ \\
\hline \multicolumn{4}{|l|}{ †Type of health problem*: } \\
\hline Infectious diseases & $29.4(26.4,32.5)$ & $29.6(26.8,32.6)$ & $34.0(29.0,39.3$ \\
\hline Non-infectious diseases & $47.6(44.1,51.1)$ & $40.0(36.5,43.3)$ & $39.2(33.7,45.0$ \\
\hline Injury and/or poisoning & $6.2(4.9,7.9)$ & $6.1(4.7,7.9)$ & $6.5(4.3,9.6)$ \\
\hline Other: symptoms, signs and abnormal findings & $16.8(14.4,19.5)$ & $24.3(21.4,27.5)$ & $20.3(16.5,24.7$ \\
\hline \multicolumn{4}{|l|}{ tPerception of severity of health problem: } \\
\hline Mild & $33.2(30.1,36.4)$ & $32.3(29.3,35.6)$ & $30.9(26.2,36.1)$ \\
\hline Moderate & $33.7(30.3,37.4)$ & $30.8(28.0,33.8)$ & $30.8(25.8,36.3$ \\
\hline Severe & $33.1(29.7,36.5)$ & $36.9(33.5,40.1)$ & $38.3(32.6,44.3$ \\
\hline $\begin{array}{l}\text { thealth services utilisation to resolve a health } \\
\text { problem that happened within the past } 15 \text { days }\end{array}$ & $78.4(75.2,81.2)$ & $60.2(56.5,63.8)$ & $55.3(50.1,60.4$ \\
\hline †Use of medicines within the past 15 days ${ }^{*}$ & $87.8(85.5,90.1)$ & $79.1(76.1,81.8)$ & $78.9(74.8,82.5)$ \\
\hline Hospitalisation within the last year* & $7.9(7.0,8.9)$ & $6.3(5.6,7.0)$ & $3.4(2.6,4.3)$ \\
\hline
\end{tabular}

vulnerable than SSHI affiliates. The differences among older adults with SSHI and SPHI and without HI are due in part to the circumstances of each HI. Mexico's SS was designed to provide comprehensive social, economic and health benefits to affiliates since it was created in 1943. Therefore, there is a cumulative effect of SSHI benefits on the affiliated population. The noncontributory health and social programmes try to bridge the gap in benefits, but these programmes were established more recently than SS, and they are supported through more limited public resources.

The analysis also served to identify that the percentage of older adults with physical and mental limitations and chronic diseases is higher among those with HI than in those without HI. One possible explanation for this finding is that older adults with physical and mental limitations and chronic diseases could be prompted to search for HI to be able to receive healthcare (through adverse selection). These conditions are permanent and represent a continuous economic burden. Another possible explanation of the higher percentage of older adults with HI suffering from a chronic condition is because they have access to screening and diagnostic procedures. It is possible that the study underestimates these conditions in the population without HI since these people might be unaware of suffering from a chronic condition due to their lack of healthcare access. The health status of older adults represents an aggregated effect of circumstances over the life period, and it is well known that the worst-off have a poorer health status. $^{27}$

Overall, the percentages of older adults lacking access to healthcare, and households experiencing financial hardship due to health expenditures were low. These results signal a positive effect of current health and social policies in Mexico. Before the introduction of SP in $2003,60 \%$ of the population had no access to HI and $3.8 \%$ of households suffered catastrophic health expenditures. ${ }^{28}{ }^{29}$ The results of this study show a decrease in the population without $\mathrm{HI}$ to $17.8 \%$, and a decrease in catastrophic health expenditures to $3.2 \%$ in SPHI affiliates. Nonetheless, differences still exist between people with and without SS. Our finding of the decrease in catastrophic health expenditures is consistent with the 
Table 3 Access to healthcare, perceived barriers for the access and financial burden by type of health insurance (ENSANUT 2012)

\begin{tabular}{|c|c|c|c|}
\hline & \multicolumn{3}{|c|}{ Health insurance (HI) } \\
\hline & Social Security & Seguro Popular & Without HI \\
\hline \multicolumn{4}{|l|}{ Number of respondents } \\
\hline Unweighted & 1398 & 1408 & 505 \\
\hline Weighted & 868219 & 661154 & 286985 \\
\hline \multirow[t]{2}{*}{ Per cent } & 47.8 & 36.4 & 15.8 \\
\hline & Weighted \% & Weighted \% & Weighted \% \\
\hline Access to healthcare*, \% & $90.2(87.8,92.1)$ & $74.6(71.1,77.8)$ & $70.9(65.5,75.8)$ \\
\hline †Perceived barriers for access & & & \\
\hline \multicolumn{4}{|l|}{ Number of respondents } \\
\hline Unweighted & 160 & 372 & 157 \\
\hline Weighted & 85246 & 168134 & 83563 \\
\hline$\%$ & 25.3 & 49.9 & 24.8 \\
\hline Financial* $^{*}$ & $10.2(5.6,17.9)$ & $38.7(32.5,45.2)$ & $57.8(48.1,66.8)$ \\
\hline Personal & $33.5(25.3,42.8)$ & $30.4(24.0,37.7)$ & $21.0(14.3,29.7)$ \\
\hline Organisational & $12.4(6.8,21.5)$ & $12.8(9.0,17.9)$ & $6.3(2.7,14.0)$ \\
\hline Lack of satisfaction with & $12.0(7.4,19.0)$ & $8.0(4.8,13.2)$ & $5.6(2.5,12.4)$ \\
\hline \multicolumn{4}{|l|}{ providers' behaviour* } \\
\hline Geographic distances* & $4.9(2.1,11.2)$ & $11.8(7.5,18.1)$ & $5.5(2.7,10.8)$ \\
\hline \multicolumn{4}{|l|}{ Number of households } \\
\hline Unweighted & 5915 & 5087 & 2178 \\
\hline Weighted & 4062675 & 2393937 & 1341230 \\
\hline$\%$ & 52.1 & 30.7 & 17.2 \\
\hline \multicolumn{4}{|l|}{ Financial burden } \\
\hline Catastrophic health expenditures* & $2.2(1.7,2.7)$ & $3.2(2.5,4.0)$ & $3.9(3.0,5.2)$ \\
\hline $\begin{array}{l}\text { Using savings, borrowing money, } \\
\text { or selling assets to pay for healthcare* }\end{array}$ & $14.8(13.5,16.1)$ & $20.0(18.4,21.8)$ & $17.9(15.7,20.2)$ \\
\hline
\end{tabular}

report of Knaul et $a l^{23}$ and it is lower than the levels found in Chile (14.4\%) and Guatemala (11.6\%).

The lack of insurance can result in non-utilisation of needed services due to financial constraints. ${ }^{30}$ In our study, $57.8 \%$ of patients without HI did not use healthcare services due to financial barriers, despite their reports of having a health problem. SPHI and SSHI affiliates also reported financial barriers, but the percentage was much lower $(38.7 \%$ and $10.2 \%$, respectively). Although these percentages were calculated only among those who reported having a health need and not utilising healthcare services (the denominator is a small fraction of the population), it shows that if a person cannot afford healthcare, this situation limits the access to health services and makes it difficult to satisfy health needs.

For HI schemes, an important equity dimension is the degree to which it promotes social solidarity in terms of healthcare financing. Extensive financial pooling through a single-pipe mechanism allows vertical redistribution between income groups so that higher income households subsidise the cost of medical care for lower income families (vertical equity) and horizontal equity means that those with the same ability to pay contribute the same amount for medical care.$^{30} 31$ In Mexico, SSHI follows the principle of vertical equity, since payment is progressive and tied to the salary. SPHI is a tax-based programme; thus, all taxpayers contribute, but the benefits are more limited than what is covered through SS.

Variations in access to healthcare, the range of insured benefits, and the size of OOPHE determine the degree to which health policy outcomes are more or less equitable. $^{5}$ The analysis of PSM showed the protective effect of SPHI against lack of healthcare access when compared with those without HI, although the protective effect of SSHI was higher. Regarding financial protection, SSHI showed a significant protective effect in comparison with those without HI and with SPHI. Our results differ from the recent study of Ávila-Burgos $e t a l,{ }^{21}$ which analysed the effect of SPHI on the probability of health spending and the amount of health spending, comparing households with SPHI with those without HI (also using ENSANUT 2012 data). That study applied PSM for the sample of 12250 households (6125 with SPHI and 6125 without HI) with members of different age groups, and found that SPHI had a protective effect for excessive OOPHE (36\% excessive OOPHE reduction), defining the excessive OOPHE as $\geq 30 \%$ of total household expenditure. ${ }^{21}$ Another study analysed the effect of $\mathrm{HI}$ on the probability and amount of OOPHE for medicines (using data from the 2008 Mexican National Household Survey of Income and 


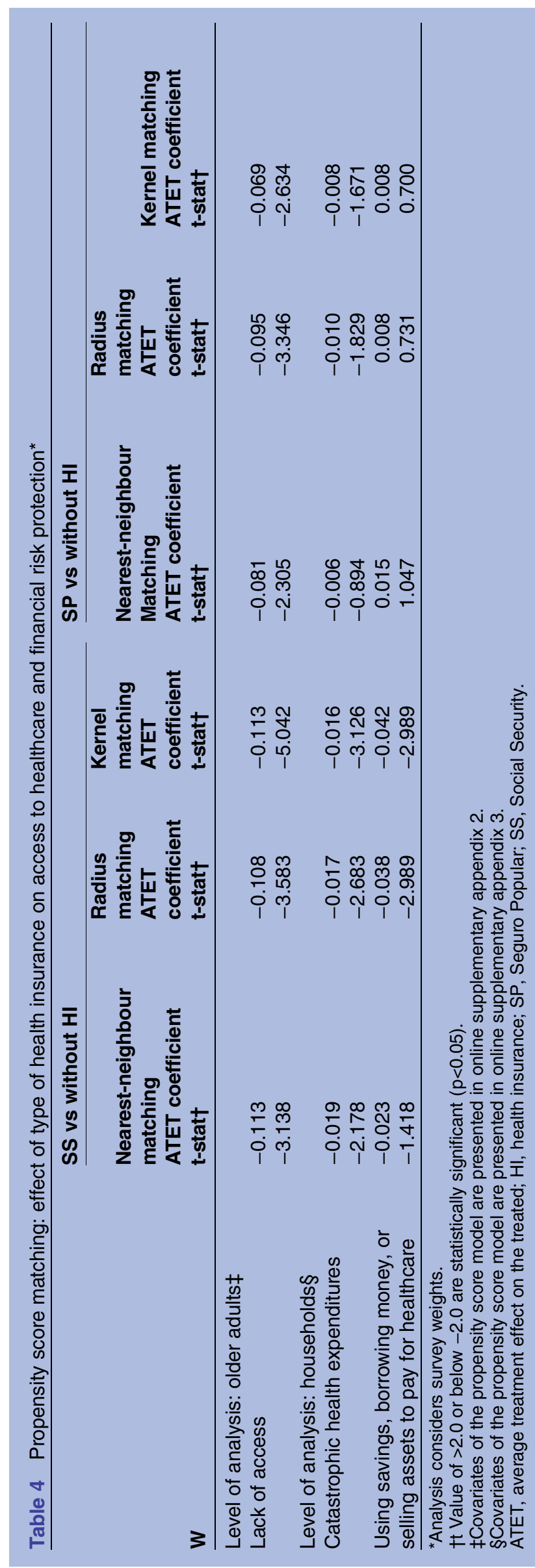

Expenditures). This study reported heterogeneity in the HI effect on the proportion of OOPHE for medicines, with a reduction of $1.7 \%$ for households with $\mathrm{SS}, 1.4 \%$ for mixed affiliation, but no difference between SP and matched households without insurance. ${ }^{32}$ In theory, SP affiliates are entitled to receive medicines for free and without copayment; nonetheless, the supply of medicines for these patients does not reach more than $70 \%$, showing that some patients with SPHI purchased their medicines in the same way as those without HI. OOPHE for medicines show that people are willing to pay and can afford medicines, regardless of the source (income, savings, borrowing money or selling assets), whereas those who do not purchase medicines probably are not willing or do not have the resources to pay.

New policies aimed at achieving more equity between those with and without SS are still needed in Mexico. Other studies performed in Latin American countries found that HI and health system operations mediate the link between economic inequality and inequitable access to healthcare. ${ }^{10}$ Different studies have shown that SP aimed at promoting demand, but this effort was not accompanied by strengthening the supply of services to reduce barriers of access to healthcare. ${ }^{7} \quad 9 \quad 33$ The package of benefits of SP is explicit, and it is periodically revised and increased, but it does not match the package provided by SS, which is not explicit but covers all healthcare conditions for older adults. The Ministry of Health facilities providing healthcare to SP affiliates are not growing in parallel with the demand. ${ }^{7} 933$ The structure and processes of care have experienced few changes, particularly in primary care settings, and despite the construction of new hospitals, the $\mathrm{MoH}$ does not have an integrated network capable of providing continuous and coordinated care to SP affiliates. To date, management for results does not occur within SP due to financial and technical limitations, such as the lack of a robust health information system. Policies focused on strengthening current healthcare services, in particular, primary care services, and on promoting an integrated network of services, would contribute to improving access and reducing the financial burden of older adults.

This study also has some limitations. First, the financial burden variables consider OOPHE that can include those of other household members; however, it seems reasonable to assume that older adults spent more for healthcare than younger household members. Second, access to healthcare was defined taking into account only the need for treatment services, although the concept of health-related needs is wider and includes access to preventive and rehabilitation services among others. Third, when calculating OOPHE, we assumed a relatively similar use of healthcare (and utilities) regardless of season, which may or may not be true. Fourth, PSM is a statistical approach that reduces overt selection bias owing to observed differences among study groups; nevertheless, it does not permit controlling for hidden 
unobserved differences. ${ }^{34}$ Therefore, we cannot rule out the existence of unobserved variables that differ between the two groups and affect outcomes. Finally, the $\mathrm{HI}$ affiliation status was self-reported, which may lead to some misclassification of those without HI, as SPHI is practically available for all people without SS when requested in facilities belonging to the Ministry of Health. Although $66.1 \%$ of older adults without HI reported using private doctors, $90 \%$ of those affiliated with SSHI reported using SS facilities, and $87.4 \%$ of those with SPHI reported using Ministry of Health facilities; these figures could be considered as a proxy to confirm their affiliations.

In conclusion, in Mexico, SPHI showed a protective effect against lack of access to healthcare for Mexican older adults. In addition, SSHI showed a significant protective effect against lack of access and financial burden compared with those with SPHI and without HI.

\author{
Author affiliations \\ ${ }^{1}$ Takemi Program in International Health. Harvard T.H. Chan School of Public \\ Health, Boston, Massachusetts, USA \\ ${ }^{2}$ Epidemiology and Health Services Research Unit, CMN Siglo XXI, Mexican \\ Institute of Social Security, Mexico City, Mexico \\ ${ }^{3}$ Division of Social Protection and Health, Inter-American Development Bank, \\ Mexico City, Mexico \\ ${ }^{4}$ Department of Global Health and Population, Harvard T.H. Chan School of \\ Public Health, Boston, Massachusetts, USA \\ ${ }^{5}$ Takemi Program in International Health. Department of Global Health and \\ Population, Harvard T.H. Chan School of Public Health, Boston, \\ Massachusetts, USA
}

Acknowledgements This project was conducted with the support of the Takemi Program in International Health at Harvard TH Chan School of Public Health. The authors also thank Simo Gozhev from the Harvard Research Technology Consulting Group for statistical assistance.

Contributors SVD and RP-C conceptualised the study. DC proposed the statistical approach. SVD conducted the literature review. SVD analysed and interpreted the data and also wrote the first draft of the manuscript. RP-C, DC and MRR critically reviewed the manuscript for significant intellectual content. All authors approved the final manuscript.

Competing interests None declared.

Ethics approval This study is a secondary data analysis of the ENSANUT 2012. The data for the analysis were requested and obtained from the survey'ss public repository hosted at the National Institute of Public Health webpage at: http:// ensanut.insp.mx/. This repository has the data already deidentified; thus, it is not possible to trace any of the data to the actual individual. In accordance with the Internal Regulation of the Research Ethics Committee of the National Institute of Public Health, this secondary analysis was considered exempt from approval.

Provenance and peer review Not commissioned; externally peer reviewed.

Data sharing statement This article has supplementary files (see online supplementary appendix 1, 2 and 3). The ENSANUT 2012 data are available at: http://ensanut.insp.mx/. The STATA code used for inferential analysis can be made available on request.

Open Access This is an Open Access article distributed in accordance with the Creative Commons Attribution Non Commercial (CC BY-NC 4.0) license, which permits others to distribute, remix, adapt, build upon this work noncommercially, and license their derivative works on different terms, provided the original work is properly cited and the use is non-commercial. See: http:// creativecommons.org/licenses/by-nc/4.0/

\section{REFERENCES}

1. National Institute of Statistics, Geography and Informatics (INEGI). Older adults in Mexico. Mexico, DF: INEGI, 2010.

2. Organization for Economic Co-operation and Development (OECD). Pensions at a glance 2013: OECD and G20 indicators, OECD publishing. (accessed 1 Aug 2014).

3. Secretary of Social Development (SEDESOL). First quarterly report 2013. Benefits programs of the administrative branch 20. Mexico, DF: SEDESOL, 2013

4. Maurer J. Assessing horizontal equity in medication treatment among elderly Mexicans: which socioeconomic determinants matter most? Health Econ 2008;17:1153-69.

5. Wong R, Díaz JJ. Health care utilization among older Mexicans: health and socioeconomic inequalities. Salud Publica Mex 2007;49 (Suppl 4):505-14.

6. Mexican Institute of Social Security. Report to the federal executive and the Congress of the Union on the financial situation and the risks of the Mexican Institute of Social Security 2012-2013. Mexico, DF, 2013.

7. Ministry of Health. System for Social Protection of Health. Performance Report January-June 2014. Mexico, DF, 2014.

8. Ministry of Health. Health sector program 2013-2018. Diario oficial de la federación. Mexico, DF: SEGOB, 2013.

9. Muñoz O, Rodríguez E, Pérez-Cuevas R, et al. Proposal for a national health services. México, DF, UNAM Seminario sobre Medicina y Salud. Mexico, 2012.

10. Wallace SP, Gutiérrez VF. Equity of access to health care for older adults in four major Latin American cities. Rev Panam Salud Publica 2005;17:394-409.

11. Salinas-Rodríguez A, Manrique-Espinoza B, Moreno-Tamayo K, et al. Aging and disability: economic implications for households in Mexico. México, DF: En: Gutiérrez Robledo LM, Lezama Fernández MA (coords.) Propuesta para un plan de acción en envejecimiento y salud. Serie: Cuadernillos de salud pública. Instituto Nacional de Geriatría, 2013.

12. Braveman P. Health disparities and health equity: concepts and measurement. Annu Rev Public Health 2006;27:167-94.

13. Andersen RM, Davidson PL. Improving access to care in America: individual and contextual indicators. In: Andersen RM, Rice T, Kominski J, eds. Changing the US health care system: key issues in health services, policy, and management. San Francisco: Jossey-Bass Publishers, 2001:3-31.

14. Romero-Martínez M, Shamah-Levy T, Franco-Núñez A, et al. National Health and Nutrition Survey 2012: design and coverage. Salud Pub Mex 2013;55(Suppl 2):332-40.

15. Wagner AK, Johnson Graves A, Reis SK, et al. Access to care and medicines, burden of healthcare expenditures and risk protection: results from the World Health Survey. Health Policy 2011;100:151-8.

16. Xu K. Distribution of health payments and catastrophic expenditures: methodology. Discussion paper EIP/HSF/DP.05.2. Geneva: World Health Organization, 2005.

17. National Population Council (CONAPO). Index of marginalization by locality. http:/www.conapo.gob.mx/es/CONAPO (accessed 10 Feb 2014).

18. Gutierrez JP. Household socioeconomic classification in the National Health and Nutrition Survey 2012. Salud Pub Mex 2013;55(suppl 2):341-6.

19. Khandker SR, Koolwal GB, Samad HA. Handbook on impact evaluation: quantitative methods and practices. The International Bank for Reconstruction and Development. Washington: The World Bank, 2010.

20. Dugoff EH, Schuler M, Stuart EA. Generalizing observational study results: applying propensity score methods to complex surveys. Health Serv Res 2014;49:284-303.

21. Ávila-Burgos L, Serván-Mori E, Wirtz VJ, et al. Effect of Seguro Popular on health expenditure in Mexican households ten years after its implementation. Salud Pub Mex 2013;55(Suppl 2):91-S9.

22. Li Y, Wu Q, Xu L, et al. Factors affecting catastrophic health expenditure and impoverishment from medical expenses in China: policyimplications of universal health insurance. Bull World Health Organ 2012;90:664-71.

23. Knaul FM, Wong R, Arreola-Ornelas $\mathrm{H}$, et al. Network on Health Financing and Social Protection in Latin America and the Caribbean (LANET). Household catastrophic health expenditures: a comparative analysis of twelve Latin American and Caribbean Countries. Salud Pub Mex 2011;53(suppl 2):85-95. 
24. Rubin DB, Thomas N. Matching using estimated propensity scores: relating theory to practice. Biometrics 1996;52:249-64.

25. King G, Gakidou E, Imai K, et al. Public policy for the poor? a randomised assessment of the Mexican universal health insurance programme. Lancet 2009;373:1447-54.

26. Galarraga O, Sosa-Ruba S, Salinas-Rodrlguez A, et al. Health insurance for the poor: impact on catastrophic and out-of-pocket health expenditures in Mexico. Eur $J$ Health Econ 2010;11:437-47.

27. Diderichsen F, Andersen I, Manuel C, et al. Working Group of Danish Review on Social Determinants of Health. Health Inequality - determinants and policies. Scand J Public Health 2012;40(Suppl 8):12-105.

28. Frenk J, Gonzalez-Pier E, Gómez-Dantes $\mathrm{O}$, et al Comprehensive reform to improve health system performance in Mexico. Lancet 2006;368:1524-34
29. Pérez-Rico R, Sesma-Vázquez S, Puentes-Rosas E. Catastrophic health expenditures in Mexico: comparative study by social exclusion level. Salud Pub Mex 2005;47(Suppl 1):47-53.

30. Wong J. Democratization and the welfare state. In: Wong J, ed. Healthy democracies: welfare politics in Taiwan and South Korea. New York: Cornell University Press, 2004:1-18.

31. Culyer AJ. Need: the idea won't do - but we still need it. Soc Sci Med 1995;40:727-30.

32. Wirtz VJ, Santa-Ana-Tellez Y, Servan-Mori E, et al. Heterogeneous effects of health insurance on out-of-pocket expenditure on medicines in Mexico. Value Health 2012;15:593-603.

33. Bossert T, Blanchet N, Sheetz S, et al. Comparative review of health system integration in selected countries in Latin America. (technical note 585). Washington: Inter-American Development Bank, 2014.

34. Austin PC. An introduction to propensity score methods for reducing the effects of confounding in observational studies. Multivariate Behav Res 2011;46:399-424. 